\title{
Evaluating the Efficiency of Chlorine Removal from Potable Tap Water using Off-gassing, Boiling, and Filtration Treatment Methods
}

\author{
Katrina Wong ${ }^{1}$, Helen Heacock ${ }^{2}$, Frederick Shaw ${ }^{3}$ \\ ${ }^{1}$ Lead author, B. Tech Student, School of Health Sciences, British Columbia Institute of technology, 3700 Willingdont Ave, Burnaby, BC V5G \\ $3 \mathrm{H} 2$ \\ ${ }^{2}$ Supervisor, School of Health Sciences, British Columbia Institute of Technology, 3700 Willingdont Ave, Burnaby, BC V5G 3H2 \\ ${ }^{3}$ Laboratory Manager, School of Health Sciences, British Columbia Institute of Technology, 3700 Willingdont Ave, Burnaby, BC V5G 3H2
}

\begin{abstract}
Background: One of the most frequent complaints to water distribution systems is the taste and odor of chlorine in consumer tap water. Chlorine is a common disinfectant used to inactivate and breakdown microbes and other contaminants. However, excess chlorine can result in an unpalatable chlorinous taste and odor. When water taste becomes too objectionable, consumers may search for alternative water sources, such as raw, untreated water that does not contain chemical additives. Raw, untreated water contains various contaminants, including disease-causing pathogens. To encourage consumers to drink treated tap water, and prevent disease, this study evaluated and compared the effectiveness of off-gassing, boiling and filtration as dechlorination methods for consumers to perform on their tap water.
\end{abstract}

Method: Hach Method 8021 was performed to collect and analyse water samples following treatment with Off-gassing, Boiling and Filtration. Water samples were collected from BCIT SW11230. The Hach Pocket Colorimeter TM II determined the free chlorine concentration of the water samples, and compared to a sample of untreated chlorinated tap water to see which method reduced chlorine concentrations the most.

Results: Mean concentration of chlorine following off-gassing was determined to be $0.51 \mathrm{ppm}$, $0.24 \mathrm{ppm}$ following boiling, and $0.55 \mathrm{ppm}$ following filtration. It was determined that the boiling method was statistically significantly different from the mean values of chlorine concentration from the other two methods, as shown by the Kruskal-wallis test $(\mathrm{P}=0.000)$, and therefore was the most effective in dechlorinating tap water samples. This was further confirmed by the Scheffe's Mutliple-Comparison Test and eyeball test.

Conclusion: Based on the results, boiling water is the most effective method to dechlorinate potable tap water for consumer acceptability. The free chlorine levels found post-boiling were also found to be below the WHO's threshold for tasting and smelling chlorine in drinking water $(0.3 \mathrm{ppm})$, and above WHO's minimum required $0.2 \mathrm{ppm}$ chlorine residual. Therefore, drinking water following boiling will be safe for consumption, as well as free of chlorinous taste and smell. Public Health professionals can safely advise consumers of an effective method to encourage treated tap water consumption, and to discourage finding alternative water sources.

Keywords: Free chlorine, off-gassing, boiling, filtration, dechlorination, chlorine residual 


\section{INTRODUCTION}

A reliable drinking water supply that is safe to consume and free from hazardous contaminants are essential for individual and community wellbeing. Unfortunately, naturally occurring water supplies, such as lakes, rivers and groundwater, are typically dangerous to consume (1). They contain disease-causing microorganisms, known as pathogens, that are typically associated with gastrointestinal-related symptoms (2). The World Health Organization (WHO) has outlined important water-borne pathogenic microorganisms (3):

TABLE 1. Water-borne Pathogenic Microorganisms of High Health Significance (from Ingestion)

\begin{tabular}{|l|l|l|}
\hline \multicolumn{1}{|c|}{ Bacteria } & \multicolumn{1}{c|}{ Viruses } & \multicolumn{1}{c|}{ Protozoa } \\
\hline Campylobacter & Adenoviruses & Acanthamoeba spp. \\
\hline Escherichia coli & Enteroviruses & $\begin{array}{l}\text { Cryptosporidium } \\
\text { parvum }\end{array}$ \\
\hline Salmonella spp. & Hepatitis A and E & $\begin{array}{l}\text { Entamoeba } \\
\text { histolytica }\end{array}$ \\
\hline Shigella spp. & $\begin{array}{l}\text { Noroviruses and } \\
\text { Sapoviruses }\end{array}$ & Giardia intestinalis \\
\hline Vibrio cholera & Rotaviruses & Toxoplasma gondii \\
\hline Yersinia spp. & & \\
\hline
\end{tabular}

While the severity of illness depends on the causative agent, typical symptoms include diarrhea, stomach cramps, nausea, vomiting and fever (4). However, people with a weakened immune system, children, the elderly, or pregnant women are at greater risk of severe reactions or serious complications, sometimes resulting in death (4). The WHO has noted that waterborne gastrointestinal diseases resulted in two million deaths annually (5).

To ensure safe drinking water is delivered to consumers, it is important that natural water sources be properly managed and treated. In Canada, water is taken from a natural water source, as mentioned previously, and treated with one or more methods to prevent waterborne diseases; one of the most common treatment methods is disinfection by chlorination (6). In 2013 alone, chlorination was used in $96 \%$ of all Canadian water treatment plants (1). The reason why chlorine is so widely accepted and used can be attributed to its strong ability to disinfect water by inactivating various types of pathogens (7). When chlorination systems malfunction or are not properly managed, waterborne illness outbreaks often arise. The E. coli outbreak at Walkerton, Ontario in May, 2000, considered in Canadian history as one of the worst public health disasters involving municipal water, is a perfect example of this $(8,9)$.

Unfortunately, chlorinated water is often accompanied with an undesirable smell and taste (10). This objectionable smell and taste is caused when there are excess amounts of chlorine in the water system (10). While chlorine levels in Canadian water system are typically well below the level normally considered to be a health concern for humans, when drinking water becomes too unpalatable due to chlorinous tastes and odors, consumers may regard this as unsafe and turn to an alternative drinking water source (10). These sources may potentially present a greater health risk as they may not be effectively treated, and therefore may contain any or all of the aforementioned pathogenic organisms. Evidently, WHO considers consumer acceptability when recommending water treatment standards (10). A current concern in Canadian public health is the emerging trend of Metro Vancouver residents drinking raw, untreated water from local ponds and springs as an alternative drinking source (11). It is believed by these residents that drinking water from a natural source is a healthy alternative due to the fact that it does not contain the "chemical" taste and odors associated with chlorine (11). Unfortunately, there is currently no information as to how far this trend has spread in Canada, although public health professionals are actively discouraging this activity $(11,12)$.

Public health professionals are significantly involved in educating consumers regarding drinking water. Accordingly, when consumers are concerned about the objectionable chlorine taste and odor, it is important for public health professionals to provide advice for the consumers on how they can remove these aesthetic issues, namely by dechlorinating their drinking water at their taps. The purpose of this study is to evaluate and compare the effectiveness of three dechlorination methods on potable tape water. The methods selected for this study were determined with consumers in mind, and are 
therefore relatively easy and affordable to perform. Results from this study have the potential for knowledge translation into educational materials for public health professionals to use throughout Canada. In this paper, chlorine and free chlorine will be used interchangeably, unless otherwise specified.

\section{LITERATURE REVIEW}

\section{Public Health Significance}

The notion that drinking water is essential for healthful living, and should therefore be safe for consumption, seems intuitive in this day and age. Proper treatment and disinfection of source water is essential in removing unwanted contaminated, such as pathogens.

Chlorine, one of the most widely used disinfection methods, is a strong disinfecting and oxidizing agent, meaning it readily inactivates most microorganisms and breakdowns other contaminants (13). However, as chlorine enters the water distribution system and combines with contaminants (referred to as "combined chlorines"), and is unable to further react with any other contaminants for disinfection or oxidation purposes $(14,15)$. As a result, there is a potential for microbiological regrowth if inadequate levels of chlorine are added (15). Accordingly, chlorine must be continually added from the water distribution system in concentrations that will allow adequate levels of chlorine residual ${ }^{1}$ to reach the taps of homes, institutions and businesses - from source to tap, drinking water must be effectively disinfected for safe consumption $(10,15)$.

\section{Legislation and Guidelines}

a. Canadian Drinking Water Guidelines

\footnotetext{
${ }^{1}$ Chlorine residual: chlorine that remains in the water distribution system after initial application; it is free to react with contaminants for disinfection and oxidation purposes, and is
}

The 2017 Guidelines for Canadian Drinking Water Quality has been published by Health Canada, and outlines the acceptable parameters for potable water in Canada (16). The guideline considers health effects, aesthetic objectives, treatment process operation, and effects on distribution infrastructure (2).

Currently, there are no maximum acceptable concentrations (MAC) for free or total chlorine ${ }^{2}$ in Canadian drinking water distribution systems (16)(16). This is because typical levels of free chlorine in Canadian drinking water ranges from 0.04-2.0 ppm (16).

\section{b. WHO Guidelines for Drinking-Water Quality}

WHO has set formal guidelines values for drinking water disinfectants. Total chlorine guideline value should be $5 \mathrm{ppm}$. For effective disinfection, chlorine residual (free chlorine) concentrations should be $\geq 0.5 \mathrm{ppm}$ throughout the distribution system, and no less than $0.2 \mathrm{ppm}$ (10).

The threshold for tasting or smelling chlorine is below the guideline value of $5 \mathrm{ppm}$, sometimes at levels as low as $0.3 \mathrm{ppm}(10)$.

\section{Public Perception of Chlorine in Drinking Water}

A survey conducted in the United States and Canadian drinking water treatment plants found that complaints regarding chlorine odor was the most frequently reported problem, and chlorine taste was the third most frequently reported problem (17).

Consumers generally have a negative opinion of the chlorine tastes and odors in their drinking water (18). Due to these aesthetic issues, consumers typically have low satisfaction from drinking their tap water, as they may associate the

therefore sometimes referred to as "free chlorine" (42).

2 Total chlorine: the total concentration of chlorine in water. It is determined by adding the level of free chlorine and combined chlorine. 
chemical taste with a lack of safety and health (18). For instance, water filter manufacturers often perpetuate the idea that chlorine can cause cancer, and are then likely to then recommend their products as a solution (19). As a result, many consumers opt to switch from drinking tap water to other alternatives, such as bottled water or untreated water reservoirs despite the negative environmental and health effects associated with these options, respectively (10)(20).

As mentioned previously, raw water poses a greater risk to consumer health than drinking treated water. Raw water is untreated, and therefore disease-causing microorganisms and other contaminants have not been removed. As a result, waterborne gastrointestinal illnesses can develop in consumers and be transmitted to others in the population.

According to WHO, there are no adverse specific adverse effects associated with human exposure to chlorine in drinking water also (10). The tolerable daily intake of chlorine for an average $60 \mathrm{~kg}$ adult consuming $2 \mathrm{~L} /$ day is $4.5 \mathrm{mg} / \mathrm{L}$ (or 4.5 ppm, below the guideline value of $5 \mathrm{ppm}$, which is also a conservative value (10).

The removal of chlorine in potable tap water by consumers is safe as long as the water retains a chlorine residual of $0.2 \mathrm{ppm}$ (10).

\section{Water Dechlorination Methods}

There are various accepted methods of dechlorination. The off-gassing method is where water is left in the open for 24 hours, allowing chlorine to volatilize into the receiving air (21). The boiling method is similar to off-gassing, although chlorine volatilization rate is rapidly increased by boiling (generally this is done for 15-20 minutes) (21). According to Zhang's study, boiling tap water is able to eliminate nearly all free chlorine (22). The de-chlorination tablets method uses tablets that contain vitamin $\mathrm{C}$ (Ascorbic acid)—vitamin $\mathrm{C}$ reacts with chlorine, forming a compound that is then precipitated out of water, freeing the water of any levels of chlorine (21). However, this method requires adding more additives to drinking water, which may deter consumers further. The filtration method removes chlorine, and potentially other contaminants depending on the filter purchased (21). The best type of filter for chlorine removal are carbon filters (21). When the water with chlorine passes through the filter, the carbon absorbs the chlorine, freeing the water (21). The Brita ${ }^{\circledR}$ brand filters utilizes activated carbon and ion exchange resins that work together to filter out various impurities, resulting in purified water without any aesthetic issues affecting its quality (23). The Brita ${ }^{\circledR}$ Pitcher \& Dispenser Water Filter used in this study reduces chlorine (taste and odour), copper, mercury, cadmium, zinc and particulates (24). According to Jegatheesan et al.'s study, carbon filters were shown to be capable of reducing chlorine concentrations (25). It should be noted, however, that while these methods are shown to be effective in dechlorinating water, there are currently no studies that compare and evaluate their effectiveness.

\section{MATERIAL AND METHODS}

\section{a. Water Source and Equipment Preparation}

Potable tap water samples were collected from a potable water source in BCIT SW01-1230. Prior to sample collection, the source water was left to run from the tap for at least five minutes to allow the standing water (unchlorinated) to be flushed out, and for fresh chlorinated water to be used for the study (26). Water was determined to contain chlorine using LaMotte Chlorine Test Strips. These test strips were designed to change colors (a pink hue) with chlorine contact (see Figure 1 below) (27). Hence, only water samples determined to contain chlorine were collected for treatment and analysis. 


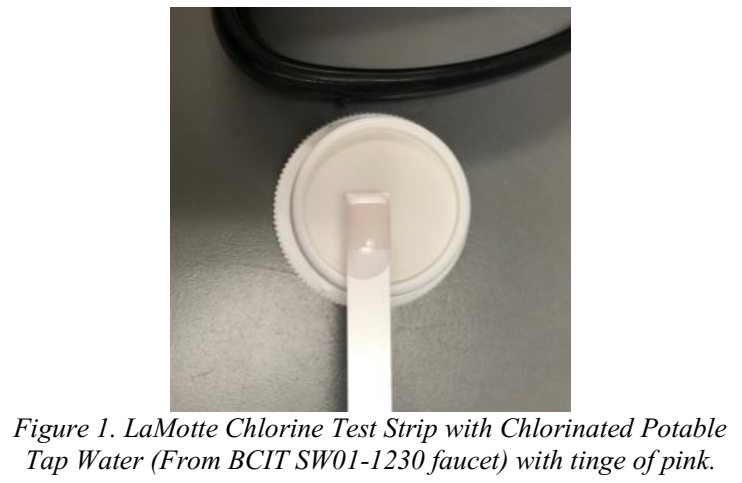

Water sample collection containers were also prepared according to manufacturer's instructions. The IKEA FARLIG clear glass pitcher with lid and Salton Variable temperature kettle was cleaned with warm water and soap and allowed to dry $(28,29)$. The Brita ${ }^{\circledR}$ Slim Water Filtration Pitcher was also cleaned with warm water and soap and allowed to dry, and the filter itself was flushed for 15 minutes $(23,30)$.

\section{b. Treatment of Potable Water}

In each water sample collection container, $1.2 \mathrm{~L}$ of potable water was collected from the BCIT water source. The water sample in the IKEA FARLIG was allowed to off-gas for 24 hour (21). The water sample in the Salton Kettle was allowed to reach boiling for 5 minutes and allowed to cool to less than $50^{\circ} \mathrm{C}$, as is required by the Hach Pocket Colorimeter TMII (21,31). The water sample in the Brita ${ }^{\circledR}$ pitcher filter was allowed to filtrate and sit for 15 minutes $(23,30)$.

\section{c. Calibration of Measuring Instruments}

Calibration of the Hach Pocket Colorimeter TM II to factory settings was done by following its user manual, Section 5.5.5 (32). Calibration to factory standards was done one time, prior to beginning this study. The Hack Colorimeter was set to the Low Range Chlorine setting.

Prior to each sample analysis, the Pocket Colorimeter TM II was calibrated against a standard to confirm consistent instrument response (33). Measurement against the standards followed the Hach Method 8021 using the SpecCheck Secondary Gel Standards Set (DPD Chlorine - LR) as the standard (see Figure 2) (26).
It is a set of four vials filled with gels that simulate the test color at various concentrations (34)(34).

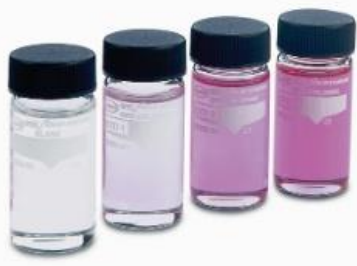

Figure 2. SpecCheck Secondary Gel Standards Set. Standards, from left to right, show blank, 1, 2, and 3 (33).

When the gel standards are set into the Pocket Colorimeter TM II, the concentrations of each respective standard must show the concentrations outlined in Table 2 (33). Results from the colorimeter showing concentrations outside the acceptable ranges indicate that the colorimeter requires recalibration to factory settings.

Table 2. SpecCheck Secondary Gel Standard chlorine

concentrations in parts per million (ppm) $(35) . S T D=$ standard.
\begin{tabular}{|c|c|c|c|}
\hline Blank & $\begin{array}{c}\text { STD 1 } \\
(\mathrm{ppm})\end{array}$ & $\begin{array}{c}\text { STD 2 } \\
(\mathrm{ppm})\end{array}$ & $\begin{array}{c}\text { STD 3 } \\
(\mathrm{ppm})\end{array}$ \\
\hline 0.00 & $0.22 \pm 0.09$ & $0.90 \pm 0.10$ & $\begin{array}{c}1.62 \pm \\
0.14\end{array}$ \\
\hline
\end{tabular}

\section{d. Sample Analysis}

The Hach Method 8021 Powder Pillow Procedure was followed (26): in the Hach Sample Cell, 10 $\mathrm{ml}$ of sample water was poured in, and one $10 \mathrm{ml}$ DPD Free Chlorine Reagent Powder Pillow was added; the sample water with the reagent was shaken for 20 seconds. Following, the Sample Cell was cleaned with KimWipes and then inserted into the Hack Pocket Colormeter II to obtain the free chlorine concentration. Thirty 10 $\mathrm{ml}$ samples were obtained from each sample water collection container for a total of 30 samples tested. Additionally, a sample of the untreated water source was taken to determine the pre-treatment chlorine concentration.

\section{Inclusion and Exclusion Criteria}

In order for water samples to be included in this study, the following parameters were required: Water samples had to be from a potable water source in SW01-1230, source water had to be run for at least five minutes, and water samples 
determined to contain chlorine using the LaMotte chlorine test strips, water samples must be placed directly put into the IKEA FARLIG glass pitcher, Salton Variable Temperature Kettle, and BRITA (R) Slim Filtration Pitcher from the source, and water samples in the IKEA FARLIG pitcher, Salton kettle, and BRITA ® Pitcher must have undergone treatment methods for off-gassing, boiling, and filtration, respectively.

All other sources of water, potentially nonchlorinated tap water, other containers, and other treatment methods were not considered in this study.

Additionally, only chlorine concentrations were measured in this study. While water samples may contain levels of minerals, heavy metals, chemicals, and particulates, they were excluded from this study.

\section{Ethical Considerations}

As no research participants were used in this study, ethical issues were limited. The main ethical considerations to take note of were to ensure the aims, objectives, information, data and results of this study were not exaggerated or presented in a misleading, biased or dishonest way, to maintain objectivity throughout this study, and to acknowledge the works of other authors or contributors to any part of this study through the referencing system as laid out in the Dissertation Handbook (36).

\section{STATISTICAL ANALYSIS}

\section{Description of Data}

In this study, ratio numerical data was collected. The concentration of chlorine was measured (in $\mathrm{ppm}$ ) before and after three methods of treatment (methods 1) off-gassing, 2) boiling, and 3) filtration). The chlorine concentrations resulting from each treatment method were compared with one another.

\section{Statistical Package}


concentration post-treatment were significantly different from one another.

The number of water samples per treatment method was 30 . The mean chlorine concentration for the following methods were determined: Offgassing reduced mean free chlorine concentrations to $0.51 \mathrm{ppm}, 0.24 \mathrm{ppm}$ following boiling, and $0.55 \mathrm{ppm}$ following filtration.

These results indicate that the Boiling method was able to dechlorinate the water samples most efficiently, compared to the Off-gassing and Filtration methods.

With reference to the inferential statistics generated by NCSS, the one-way ANOVA was interpreted to determine whether a parametric or nonparametric test was to be read. According to the Test of Normality of Residuals Assumption, it was determined normality was rejected, hence data was not normally distributed and the nonparametric test-Kruskal-Wallis One-Way ANOVA by Rank — was read.

Based on the Kruskal-Wallis test, the probability level, $p$, of the test was determined to be $p=0.000$. Since $p=0.000$ which is less than $p=0.05$, there is a statistically significant difference between the three mean values of chlorine concentration after each of the three treatment methods, and therefore the null hypothesis (Ho) was rejected.

Since Ho was rejected, the Post Hoc test of means, Scheffe's Multiple-Comparison Test was interpreted. From the results of Scheffe's test, it was determined that the mean chlorine concentration after off-gassing was statistically significantly different from both the boiling and filtration methods; mean concentration of chlorine after boiling was statistically different from off-gassing and filtration methods; and mean concentration of chlorine after filtration was statistically different from off-gassing and boiling methods. This can also be determined via the "eyeball test" of the graph below:

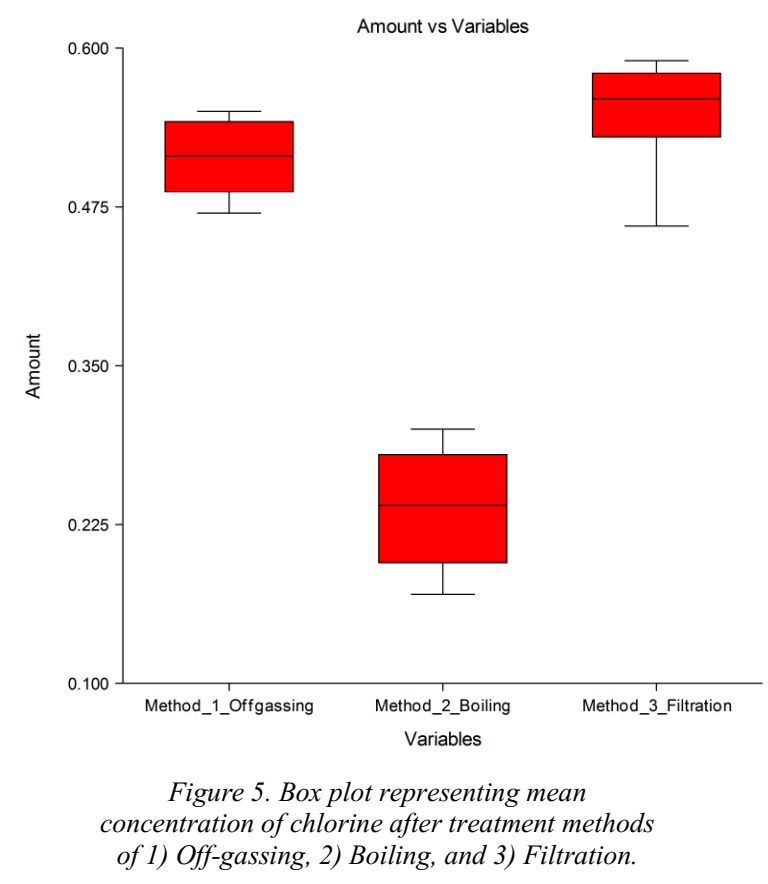

The power of this study was determined to be $100 \%$ based on the Analysis of Variance Table and F-Test.

\section{DISCUSSIONS}

\section{Findings}

The purpose of this study was to evaluate the effectiveness of three methods (off-gassing, boiling, and filtration) in removing free chlorine from potable tap water, hence removing associated taste and odor issues.

All three methods were capable of some reduction from the initial (pre-treated) free chlorine concentration of $0.69 \mathrm{ppm}$ to a mean of $0.51 \mathrm{ppm}, 0.24 \mathrm{ppm}$, and $0.55 \mathrm{ppm}$ via off-gassing, boiling and filtration, respectively.

Based on the ANOVA post-hoc test, all three methods were statistically different from one another in terms of their mean chlorine concentration, however, the boiling method provided the lowest mean chlorine concentration after treatment compared to the other two methods. Additionally, only the boiling method produced mean chlorine levels that fell below the threshold of smelling and tasting chlorine 
outlined by WHO (10). It is this below this threshold that prevents aesthetic concerns (10). Additionally, as chlorine residuals are above 0.2 ppm minimum levels recommended by WHO, water is safe still for consumption (10). Therefore, the boiling method is the best solution to offer to the public in terms of removing chlorine (and its associated taste and odor) from their taps. The other two methods produced chlorine concentrations above $0.3 \mathrm{ppm}$, and therefore should not be recommended to the public when educating them on methods in dechlorinating their tap water.

\section{Integration with other Research Findings}

While there is no one study that directly compares the effectiveness of one dechlorination method highlighted in this study to another, it can be confirmed that all methods reduced chlorine concentrations by some extent as previous research indicates. However, it should be noted that there are no studies related to the efficiency of chlorine evaporation from water in reducing chlorine concentrations, however, as chlorine is a volatile compound in water, given enough time, some amounts of chlorine will dissipate $(21)(21)$.

\section{a. Comparison with Jegatheesan et al. (2009)}

Jegatheesan et al.'s study measured combined chlorine, which the researcher refers to as chlorine demand due to fast and slow reacting organic/inorganic compounds, and the efficiency in its reduction using various filtration methods (25). In Jegatheesan et al.'s study, it was determined that the activated carbon filter did not significantly reduce the initial level of combined chlorine, but did slow the reaction rate of these compounds (25). That is, the rate production of combined chlorines was reduced.

In this study, it was found that the Brita ${ }^{\circledR}$ Pitcher, which uses an activated carbon filter, was only able to reduce $0.69 \mathrm{ppm}$ of initial free chlorine concentration to a mean $0.55 \mathrm{ppm}$. While there was some reduction, this was shown to be the highest mean concentration of chlorine posttreatment compared to the methods off-gassing $(0.51 \mathrm{ppm})$ and boiling $(0.24 \mathrm{ppm})$.
While both studies showed a reduction in chlorine concentrations, it must be noted that Jegatheesan et al.'s study measured combined chlorine, while this study measured free chlorine, therefore the results of these two studies cannot be directly compared.

\section{b. Comparison with Zhang (2013)}

In Zhang's study, it was determined that heating tap water from room temperature to boiling eliminated nearly all free chlorine, where the starting chlorine concentration was $0.5 \mathrm{ppm}$ (22). However, Zhang notes that heating and boiling tap water to remove free chlorine is an effective method only when initial chlorine concentrations are low, since reducing chlorine concentrations when initial levels are high $(>4.0 \mathrm{ppm})$ can contribute to high energy costs (22). However, Canadian drinking water is generally within the ranges of $0.4-2.0 \mathrm{ppm}$, therefore this is not an issue (16). The results from Zhang's study agrees with this study's findings, as the boiling method was also found to be extremely effective in reducing chlorine concentrations.

\section{Validity of Results}

Various measures were taken to increase the validity of the results obtained from this experiment. This included using a proven measuring instrument (Hack Pocket Colorimeter TM II, calibration of this instrument was done according to manufacturer's requirements, and a standard method in testing for free chlorine (the Hach Method 8021) was followed. Additionally, a pilot study was conducted on January 24, 2018 to ensure correct and consistent use of the instruments as well as the methodology.

However, there were two main methodological limitations that could have affected the validity of this study's results. There may have been interferences from other contaminants in the reaction of DPD with chlorine, thereby affecting the readings from the Hach Pocket Colorimeter тм II. However, most accepted chlorine measuring methods are subject to this source of error, and there is no "ideal" method for chlorine analysis (37)(37). Additionally, the filter used in this study may not have been the most effective 
filter known to be available for consumer purchase, however, this was used due to monetary constraints. Potentially, a different filter could have provided different results from this treatment method. Nevertheless, it is still clear that boiling water is an effective method in dechlorinating tap water. As such, the results from this study are valid when extrapolated to the general public for an effective dechlorination method, and to Public Health Inspectors and Drinking Water Officers when educating the public on dechlorination.

It should be noted, however, that this study's findings only takes into account the reduction in chlorine concentration via the three methods; this study does not take into account any reductions or increases in any other contaminant concentrations resulting from one or more of the aforementioned treatment methods. The filtration method using the Brita ${ }^{\circledR}$ Slim Water Filtration Pitcher also reduces Copper, Mercury, Cadmium and Zinc (38). As well, boiling water reduces water hardness, but also concentrates fluoride $(39,40)$.

Therefore, while the findings from this study can address chlorine-related aesthetic concerns, it should not be used to address other concerns the public may have pertaining to other contaminants found in tap water.

\section{LIMITATIONS}

The two main limitations in this experiment that could have potentially affected the findings from this study are elaborated below.

\section{Interferences from Other Contaminants in Water Sample}

DPD reaction with chlorine is subject to potential interferences from other contaminants, such as particulates, color, inorganic and organic compounds, and other oxidizing agents (e.g. ozone, chlorine dioxide, and bromine, which are disinfectants sometimes used in water treatment) (37). As this study only accounted for chlorine concentration, it is unknown if other potentially contaminants in the sample water may have skewed the findings from this study. However, in general, all of the common and accepted analytical methods for chlorine in water are subject to potential interferences, therefore there may not be one better method to offset this limitation (37). It may be necessary to artificially create chlorinated water by adding a calculated amount of chlorine into distilled water (which is devoid of other contaminants), and then using this water to carry out this study.

\section{Time and Monetary Constraints}

From the results obtained from this study, it is clear that the boiling method is better at dechlorinating tap water than the filtration method. However, there are various types of water filter equipment available for the consumer on the market, some potentially more effective than others. Unfortunately, there was only one filter equipment provided for this study due to monetary constraints. This Brita ${ }^{\circledR}$ Pitcher was purchased due to its inexpensive nature. As well, it was readily available for purchase, such that not much time was need to either look for a harderto-find product, or wait for delivery from an online purchase; this had to be considered due to the time constraints of this study. Potentially, other Brita ${ }^{\circledR}$ Pitchers or the Brita ${ }^{\circledR}$ Faucet Filtration System could have been more effective in reducing chlorine in tap water. The Brita ${ }^{\circledR} 10$ Cup Everyday Water Pitcher is found to be one of the five best water filter pitchers, although it is a little over twice as expensive as the pitcher used in this study (41).

\section{KNOWLEDGE TRANSLATION}

Drinking untreated (raw) water is a continually rising trend among people who have aesthetic concerns regarding chlorine, where its associated taste and odor gives consumers a misconceived notion that the water is unsafe for consumption (10). However, drinking raw water can result in various gastrointestinal illnesses to its consumers, while the concentrations of chlorine in tap water are far below levels dangerous to human health (4). As such, disincentives to drinking treated water must be lowered by providing the best method consumers can use to remove chlorine 
from their tap water, effectively eliminating the associated taste and odor issues.

The results of this study can be used by Public Health Officers and Drinking Water Officers to provide to homeowners, and the public, as a solution for their chlorine-related concerns. Information can be dispersed orally, such as when homeowners call Health Authorities for advice, or when inspecting private wells whose owners refuse to add chlorine to treat their water supply due to aesthetic concerns. Additionally, these results can also be used in educational publications aimed at educating the general public on methods to reduce chlorine levels in their concentrations.

\section{FUTURE RESEARCH}

Suggestions of future research that may further lower the barrier for the public drinking treated water may include: determining whether the dechlorination methods used in this study may provide different results using tap water from more than one source, determining whether contaminants in tap water can affect results obtained from the Hach Pocket Colorimeter TM II in this study, by comparing it to chlorinated distilled water, evaluating the effectiveness of the three methods used in this study in removing heavy metal contaminants, fluoride, chlorine, and chlorination by-products from tap water, and repeating this study using other filters.

\section{CONCLUSIONS}

From this study, it was determined that the boiling method lowered the chlorine concentration from an initial chlorine concentration of $0.69 \mathrm{ppm}$ to a mean concentration of $0.24 \mathrm{ppm}$. This was statistically significantly different from the mean chlorine concentration of $0.51 \mathrm{ppm}$ and $0.55 \mathrm{ppm}$ resulting from treatment with off-gassing and filtration, respectively. While treatment with the offgassing and filtration method were statistically different from each other as well, it is clear that the boiling method was most effective by comparison, and is the only method that produces chlorine concentrations within the range of $0.2-$ $0.5 \mathrm{ppm}$ recommended by WHO's Guidelines for Drinking Water Quality. The significance of this study's findings will provide Public Health Inspectors and Drinking Water Officers further scientific backing when providing the homeowners, private well owners, and the general public knowledge on how to dechlorinate their treated tap water, either verbally or through printed educational materials and publications. Hence, this could provide a solution for the public's concerns with the taste, odor, and any misconceived health effects associated with chlorine, thereby reducing the amount of individuals opting to drink raw, untreated water, and developing gastrointestinal diseases as a consequence.

\section{ACKNOWLEDGEMENTS}

The author would like to acknowledge Dr. Helen Heacock and Frederick Shaw for their guidance with this study: Dr. Helen Heacock for insight and knowledge pertaining to previous research by Environmental Health students, Frederick Shaw (Laboratory Manager, Environmental Health Faculty at BC Institute of Technology) for his supervision, technical assistance, and equipment and lab space towards this study.

Additionally, the author would like to thank BC Institute of Technology, Environmental Health department for supporting this study.

\section{COMPETING INTERESTS}

The authors declare that they have no competing interests.

\section{REFERENCES}
1. Statistics Canada. Environment Fact Sheets Source water quality, 2013 [Internet]. 2013 [cited 2018 Dec 1]. Available from:


https://www.statcan.gc.ca/pub/16-508x/16-508-x2015009-eng.htm

2. Health Canada. Canadian Drinking Water Guidelines [Internet]. 2016 [cited 2018

Dec 1]. Available from: https://www.canada.ca/en/healthcanada/services/environmentalworkplace-health/water-quality/drinkingwater/canadian-drinking-waterguidelines.html

3. Aspects M. Microbial Aspects. Water Borne Dis. 2005;22-8. Available from: http://www.who.int/water_sanitation_hea 1th/dwq/gdwq3_7.pdf

4. HealthLink BC. Water-borne Infections in British Columbia [Internet]. 2016. Available from:

https://www.healthlinkbc.ca/healthlinkbc -files/water-borne-infections

5. World Health Organization. Waterborne disease related to unsafe water and sanitation [Internet]. 2018. Available from: http://www.who.int/sustainabledevelopment/housing/healthrisks/waterborne-disease/en/\%0D

6. Hapke H. Drinking water and health [Internet]. Vol. 26, Toxicon. 2002.968968 p. Available from:

http://linkinghub.elsevier.com/retrieve/pii /004101018890267X

7. HealthLink BC. Drinking Water Chlorination Facts [Internet]. 2016 [cited 2018 Dec 1]. Available from: https://www.healthlinkbc.ca/healthlinkbc -files/drinking-water-chlorination

8. Hipel KW, Zhao NZ, Kilgour DM. Risk Analysis of the Walkerton Drinking Water Crisis. Can Water Resour J [Internet]. 2003;28(3):395-419. Available from: http://www.tandfonline.com/doi/abs/10.4 296/cwrj2803395

9. Salvadori M, Sontrop J, Garg A, Moist L, Suri R, Clark W. Factors that Led to the Walkerton Tragedy. PubMed. 2009;

10. World Health Organization. Guidelines for Drinking-Water Quality. 4th ed. 2017. 631 p. Available from: http://apps.who.int/iris/bitstream/handle/ 10665/254637/9789241549950eng.pdf;jsessionid=170C6AA7A8A1222
E7894D0B15BEC1167? sequence $=1$

11. Muzyka K. Raw water trend puts the "gotta go" into H2O, says U of A health professor [Internet]. CBC News. 2018 [cited 2018 Dec 1]. Available from: http://www.cbc.ca/news/canada/edmonto $\mathrm{n}$ /raw-water-tim-caulfield-universityalberta-1.4490579

12. Azpiri J, McArthur A. Some Metro Vancouver residents insist on drinking "raw water" despite health warnings [Internet]. 2018. Available from: https://globalnews.ca/news/3966855/vanc ouver-raw-water-trend/

13. Vancouver Coastal Health. PoolSmart: Protecting the Health and Safety of Pool and Hot Tub Patrons. 3rd ed. Vancouver; 2016. 187 p.

14. CDC. Disinfection with Chlorine [Internet]. 2015 [cited 2018 Dec 1]. Available from: https://www.cdc.gov/healthywater/drinki ng/public/chlorine-disinfection.html

15. Metro Vancouver. Drinking Water Treatment Process [Internet]. [cited 2018 Dec 1]. Available from: http://www.metrovancouver.org/services/ water/quality-facilities/facilitiesprocesses/treatmentprocess/Pages/default.aspx

16. Health Canada. Guidelines for Canadian Drinking Water Quality Summary Table Federal-Provincial-Territorial Committee on Drinking Water of the FederalProvincial-Territorial Committee on Health and the Environment February 2017. 2017; (February 2017).

17. Odell LH, Kirmeyer GJ, Wilczak A, Jacangelo JG, Marcinko JP, Wolfe RL, et al. American Water Works Association. 2016;88(7):86-98. Available from: https://www-jstororg.ezproxy.library.ubc.ca/stable/pdf/412 95508.pdf?refreqid=excelsior $\% 3 \mathrm{~A} 555 \mathrm{~cd}$ 560715b932a6be66bc2aec2863f

18. Puget S. Chlorine flavor perception and neutralization in drinking. 2013; Available from: https://tel.archivesouvertes.fr/tel-00786522/document

19. Scientific American. Tapped Out?: Are Chlorine's Beneficial Effects in Drinking 
Water Offset by Its Links to Cancer? [Internet]. 2018. Available from: https://www.scientificamerican.com/artic le/earth-talks-tapped-out/

20. Mackey E, Baribeau H, Crozes G, Suffet I, Piriou P. Public perception of tap water chlorinous flavor. Water Sci Technol. 2004;49(9):335-40.

21. Aquafil. How to Remove Chlorine from Water [Internet]. 2017. Available from: http://www.aquafil.com.au/how-toremove-chlorine-from-water/

22. Zhang LA. Removal of Chlorine Residual in Tap Water by Boiling or Adding Ascorbic Acid. Int J Eng Res Appl. 2013;3(5):1647-51.

23. Brita Canada. Brita Slim Water Filtration Pitcher [Internet]. 2014. Available from: https://brita.ca/using-brita/productcare/\#soaking

24. BRITA. BRITA [Internet]. 2018. Available from: https://brita.ca/waterfiltration-process/

25. Jegatheesan $\mathrm{V}$, Kim $\mathrm{SH}$, Joo CK, GAO B. Evaluating the effects of granular and membrane filtrations on chlorine demand in drinking water. J Environ Sci [Internet]. 2009;21(1):23-9. Available from: http://dx.doi.org/10.1016/S10010742(09)60006-1

26. HACH. Methods 8021 \& 8167: Free and Total Chlorine. 2017;2:1-8.

27. LaMotte. Free Chlorine Low Range Test Strips [Internet]. 2018. Available from: http://www.lamotte.com/en/waterwastewater/test-strips/2964-g.html

28. IKEA. FARLIG. 2018.

29. Salton. Variable Temperature Kettle [Internet]. 2017. Available from: https://salton.com/product/variabletemperature-kettle/

30. Brita Canada. How to Care for Your Brita Product [Internet]. 2014. Available from: https://brita.ca/using-brita/productcare/\#soaking

31. Ii C. POCKET.

32. Pathlength SC. Pocket Colorimeter ${ }^{\mathrm{TM}}$ II Colorimeter. Digestion. 2014;

33. Hach. SpecCheck Secondary Gel Standards Set, DPD Chlorine - LR
[Internet]. 2017. Available from: https://www.hach.com/specchecksecondary-gel-standards-set-dpdchlorine-lr/productdetails?id=7640204329

34. HACH. SpecCheck Secondary Gel Standards Set, DPD Chlorine - LR [Internet]. 2017. Available from: https://www.hach.com/specchecksecondary-gel-standards-set-dpdchlorine-lr/product?id=7640204329

35. HACH. Certificate of Analysis.

36. Bryman A, Bell E. Business Research Methods. Oxford Univ Press. 2007;

37. Harp DL. Current Technology of Chlorine Analysis for Water and Wastewater. Tech Inf Ser. 2002;(17):34.

38. Brita Canada. Water Quality \& Contaminants [Internet]. 2014 [cited 2018 Mar 18]. Available from: https://brita.ca/water-filtrationprocess/water-quality-contamination/

39. BBC. Hardness of water [Internet]. 2014 [cited 2018 Mar 18]. Available from: http://www.bbc.co.uk/schools/gcsebitesiz e/science/triple_ocr_gateway/chemistry out there/hardness of water/revision/1/

40. Helmenstine AM. Can You Remove Fluoride By Boiling Water? [Internet]. 2018 [cited 2018 Mar 18]. Available from: https://www.thoughtco.com/boilingremove-fluoride-3975943

41. Ross. The Best Water Filter Pitcher [Internet]. 2018 [cited 2018 Mar 18]. Available from: https://www.yourbestdigs.com/reviews/b est-water-filter-pitcher/

42. Wiant C. The Chlorine Residual: A Public Health Safeguard [Internet]. 2013. Available from:

http://www.waterandhealth.org/chlorineresidual-public-health-safeguard/

43. Wong, K. (2018). Evaluating the Efficiency of Chlorine Removal from Potable Tap Water using Off-gassing, Boiling, and Filtration Treatment Methods. BCIT Environmental Health Journal. 